\title{
Design and Fabrication of 3D Skyscraper Nanostructures and Their Applications in Biosensors
}

\author{
Guigen Zhang \\ Department of Bioengineering, Department of Electrical and Computer Engineering \\ Institute for Biological Interfaces of Engineering 301, Rhodes Engineering Research Center \\ Clemson University Clemson, SC 29634 \\ USA
}

\section{Introduction}

Biosensors are analytical devices that combine a biologically sensitive element with a physical transducer to selectively and quantitatively detect the presence as well as the amount of a specific compound in biological environments. The biosensitive element is for target recognition and the physical transducer is for signal transduction. For the biosensitive element, molecular couples such as antibody-antigen, protein-ligand, protein-aptamer, paired-nucleotides and avidin-biotin are often used, and for the physical transducer electrochemical methods such as voltammetric, impedimetric and amperometric measurements are popular choices. For example, a sensing platform using the avidin-biotin couple as the biosensitive element and an electrochemical technique as the physical transducer has been widely explored to achieve rapid, specific and sensitive detections (Ding et al., 2005; Hou et al., 2006, 2007; Lee et al., 2008).

Biosensors are important devices for monitoring biological species in various processes of environmental, food, pharmaceutical and biomedical concerns. The main challenges many biosensors face today include low sensitivity, poor specificity and proneness to fouling. The advent of nanotechnology presents some promising solutions for alleviating these problems. For example, improvements for the sensitivity and antifouling capability of biosensors have been explored through the incorporation of nanostructures into the electrodes of biosensors (Koehne et al., 2004; Wang et al., 2005; Anandan et al., 2006, 2007). Nanostructures like gold nanotubes (Delvaux et al., 2003), carbon nanotubes (Gao et al., 2003; Wang et al., 2003, 2004) and gold nanoparticles (Bharathi et al., 2001) have been incorporated into electrodes and they exhibited much improved performance than conventional flat electrodes.

Biosensors using an electrochemical method as the underlying transducer offer a costeffective and more specific means to measure the electrical responses resulted from electrochemical reactions between the sensitive element and the target analyte. In an electrochemical based biosensor, the sensitivity is related to the surface area of its electrode (Bard et al., 2001; Delvaux et al., 2003) because a large surface area is beneficial not only for enzyme immobilization but also for electron transfer. The surface area of the electrode can be increased by the use of nanostructures because the surface-to-volume ratio of a structure 
increases as its size decreases (Jia et al., 2007; Anandan et al., 2007, Gangadharan et al., 2008). Since most of these nanostructures are made of inorganic materials, to use them as electrodes they have to be functionalized for biological recognition purposes (Gangadharan et al., 2008; Lee et al., 2008). To functionalize these electrodes, biosensitive elements need to be immobilized onto the electrode surface. In many situations, biosensitive molecules cannot be immobilized directly onto the surface of these inorganic materials, thus anchoring molecules are necessary. Therefore, the ability to improve the performance of these inorganic-based nanostructured electrodes relies on not only the morphological design of the nanostructures but also the selection of anchoring molecules, aside from the effects of electrode reactions and the underlying mass transport mechanisms (Anandan et al., 2007).

To achieve high efficiency in enzyme immobilization on electrode surface, many techniques have been developed including the use of self assembled monolayer (Gooding et al., 1998, 2000; Losic et al., 2001a, 2001b; Berchmans et al., 2003), conducting polymers (Uang et al., 2002; Gao et al., 2003) and sol-gels (Qiao et al., 2005). Among these methods, the selfassembled monolayer (SAM) technique offers a better control for enzyme distribution at the molecular level and a high degree of reproducibility in enzyme immobilization (Losic et al., 2001a, 2001b; Berchmans et al., 2003). Physical entrapment of an enzyme in a porous conducting polymer film at electrode surface offers an attractive alternative. Conducting polymer like polypyrrole (PPy) can be electro- polymerized and deposited onto the electrode surface to form a porous film, providing pores large enough for efficient electron transfer (Ramanavicius et al., 2001; Gangadharan et al., 2008). Thus by mixing an enzyme in pyrrole solution, a porous polymeric film with the enzyme entrapped inside can be formed at electrode surface via electrodeposition.

However, the question remains unanswered is: how do these functionalization methods fare in enhancing the sensing performance of electrodes made of three dimensional (3D) nano structures? This chapter aims to seek an answer to this question. First, the design of highsurface-area 3D nanostructures in a skyscraper metaphor is proposed for producing structures with high surface on a limited projection area and the importance of having sufficient mechanical robustness for the 3D skyscraper structures is discussed. Then, methods to fabricate robust 3D skyscraper nanopillar structures in an aqueous process are presented. Following that, electrochemical evaluations of these 3D nanopillar structures having bare, molecularly treated, and functionalized surfaces are discussed. Finally, for comparing the two functionalization methods, two cases are discussed in which the 3D nanopillar structures are used as electrodes for glucose detection. In the first case, the 3D electrodes are functionalized through a SAM/enzyme approach in which the biosensitive enzyme (i.e., glucose oxidase, or GOx) is tethered to a SAM of anchoring molecules formed at the electrode surface, and in the second case, the 3D electrodes are functionalized through a PPy/enzyme approach in which GOx is entrapped in a porous film of PPy electrodeposited at the electrode surface.

\section{Design of high-surface-area nanostructures}

Nanostructures such as nanorods, nanowires, nanotubes and nanoparticles have been widely explored for application in biosensors because these structures offer large surface areas in addition to their unique optical, electrical and mechanical properties. For example, the use of carbon nanotubes (Wang et al., 2003, 2004; Gao et al., 2003), peptide nanotube (Yemini et al., 2005) and nanoparticles (Bharathi et al., 2001) in various biosensors resulted in 
increased signal measurements. Electrodes modified with peptide nanotubes showed a 2.5fold increase in amperometric response when compared with non-modified electrodes. Similarly, electrodes incorporated with carbon nanotubes showed a significant increase in selectivity and sensitivity for glucose detection.

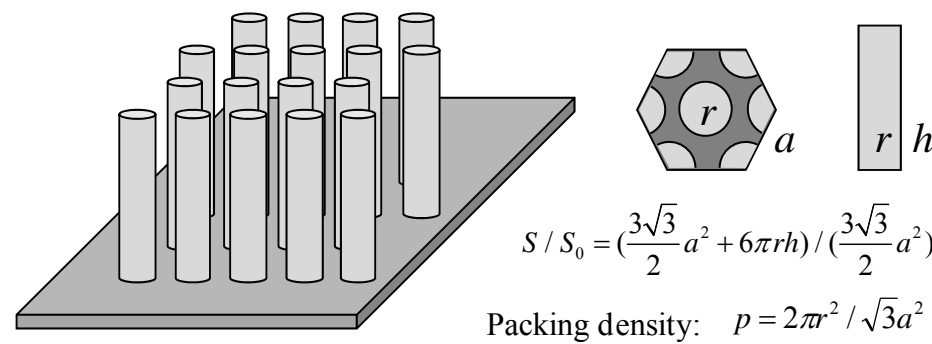

For $r=100 \mathrm{~nm}, h=5 \mu \mathrm{m}$ and $p=50 \%: \quad S / S_{0}=1+\frac{2 h}{r} p=51$

Fig. 1. Schematic illustration for increasing the overall surface area by building 3D skyscraper structures on a limited areal footprint.

One reason for the performance improvement when nanostructures are used is that these nanostructures provide large surface areas due to the fact that the surface-to-volume ratio of a structure increases as its size decreases. But when these nanostructures are formed on a planar substrate, the overall surface-area enhancement will be limited, to a certain extent, by the size of the underlying substrate. Then the question becomes: how can one achieve a higher surface area when the size of the planar area (or the 'real estate') is fixed? The answer lies in a "skyscraper" metaphor, that is, to build up within a limited areal footprint. Adding 3D skyscraper nanostructures onto a planar surface offers a significant increase in its overall surface area when compared with the planar surface. This fact can be illustrated by the example given in figure 1, where a 2D hexagonal array of vertically aligned nanorods or nanopillars is constructed on a planar substrate to form a 3D structure. At an aspect ratio $(h / 2 r)$ of 25 and a packing density $p=50 \%$ for the nanopillars, a 51-fold increase in surface area can be achieved.

To date, various 3D skyscraper nanostructures have been fabricated using chemical vapor deposition (CVD) (Lau et al., 2003), physical vapor deposition (PVD) (Fan et al., 2004) and template based electrodeposition (Forrer et al., 2000; Wang et al., 2002; Xu et al., 2004). Lately, evidence has emerged to reveal that the nanotubes and nanorods developed by the CVD and PVD techniques could not sustain the capillary forces generated by the nanostructureliquid interaction (Lau et al., 2003; Fan et al., 2004). When vertically aligned 3D nanostructures are exposed to a liquid environment, capillary forces will develop between the vertically aligned nanostructures and the liquid medium (Kralchevsky et al., 2000). If the forces are large, the nanostructures will deform or clump together. For example, the nanorods fabricated by the PVD technique in our lab deformed severely upon water exposure as shown in figure 2. Such a deformation in these 3D skyscraper nanostructures will reduce the total surface area, thus posing a serious problem for their application in functional biosensor devices because a majority of biosensors will have to be exposed aqueous environments. Therefore, to be useful as a component in a biosensor, these nanostructures need to have sufficient mechanical strength to overcome the capillary forces. 

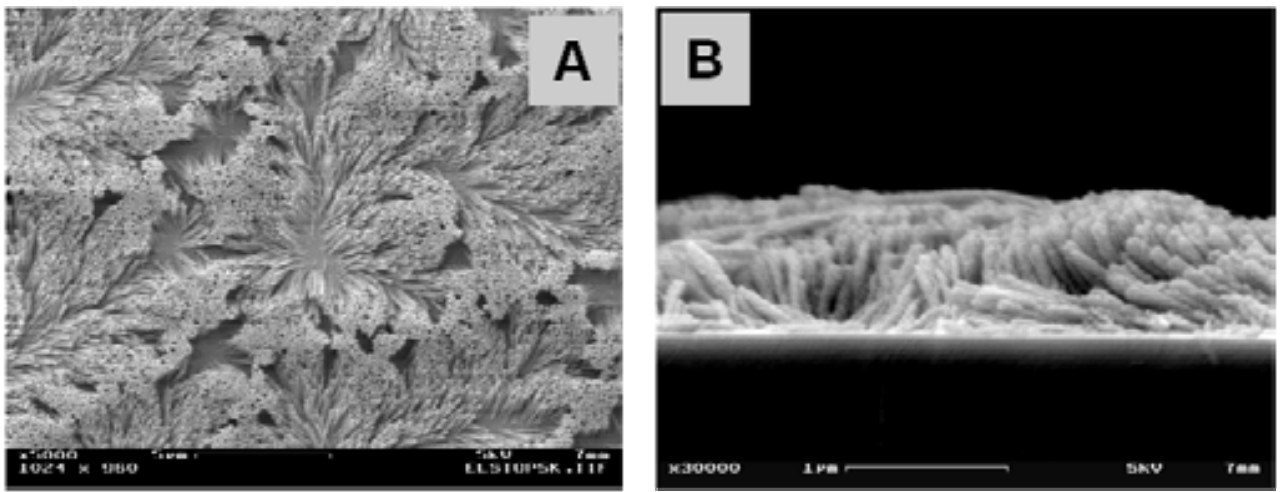

Fig. 2. Deformed 3D skyscraper silicon nanorod structures upon water exposure: (A) a top view and (B) a side view.

\section{Fabrication processes for robust 3D skyscraper nanostructures}

To overcome this problem, robust 3D skyscraper structures are necessary. One solution is to use an aqueous based fabrication technique instead of a vapor based method. We have developed a template based electrodeposition technique to fabricate 3D skyscraper nanostructures (Anandan et al., 2006, 2007). In this aqueous based fabrication method, porous anodic alumina (PAA) discs are used as templates to guide the electrodeposition of conducting materials through the pores of the PAA templates in a three-electrode electrochemical cell, in which a gold-coated PAA disc is used as working electrode, a platinum (Pt) wire gauze as counter electrode and an $\mathrm{Ag} / \mathrm{AgCl}$ electrode as reference electrode. In this fabrication process, a thin gold layer about $150 \mathrm{~nm}$ thick is first sputtercoated onto one side of a PAA disc to provide a conductive coating. Then a thicker gold layer $(\sim 3 \mu \mathrm{m})$ is electrodeposited on top of the sputtered gold film to form a strong supporting base in Orotemp24 gold plating solution (Technic Inc, Cranston, RI) at a deposition current of $5 \mathrm{~mA} / \mathrm{cm}^{2}$ for about two minutes. The supporting base is then masked with Miccrostop solution (Pyramid plastics Inc., Hope, Arkansas). After that, gold nanopillars are electrodeposited through the open pores of the PAA disc from the uncoated side at a deposition current of $5 \mathrm{~mA} / \mathrm{cm}^{2}$ at $65^{\circ} \mathrm{C}$ in the same plating solution. The deposition time can be varied for achieving nanopillars of different heights. After nanopillar deposition, the PAA disc is dissolved in $2.0 \mathrm{M} \mathrm{NaOH}$, resulting in a thin sheet structure with a $2 \mathrm{D}$ array of vertical gold nanopillars standing on a gold film.

To assess the mechanical robustness of these nanopillars, a water droplet test can be performed (Fan et al., 2004). To do that, a water droplet is placed on a 3D nanopillar structure and is allowed to dry for several hours. After that, the morphology of the nanopillars is examined under scanning electron microscopy (SEM). Figure 3 shows two SEM images of 3D gold nanopillar structures. These nanopillars have a diameter of about $150 \mathrm{~nm}$ and a height approximately $4.5 \mu \mathrm{m}$. Clearly, the nanopillars exhibited slight clumping or bunching at their top ends. This bunching phenomenon, however, is different from the collapsing type of deformation shown in figure 2. Although this bunching deformation is due to the same capillary interaction between the nanopillars and water during the removal of PAA templates, the morphology of the 3D nanopillar structures after water exposure (Fig. 3A) is found to be almost identical to that before water exposure 
(Fig. 3B). This fact indicates that exposing these nanopillar structures to water did not cause any further deformation, suggesting that the nanopillars fabricated by this aqueous based electrodeposition method are mechanically strong.
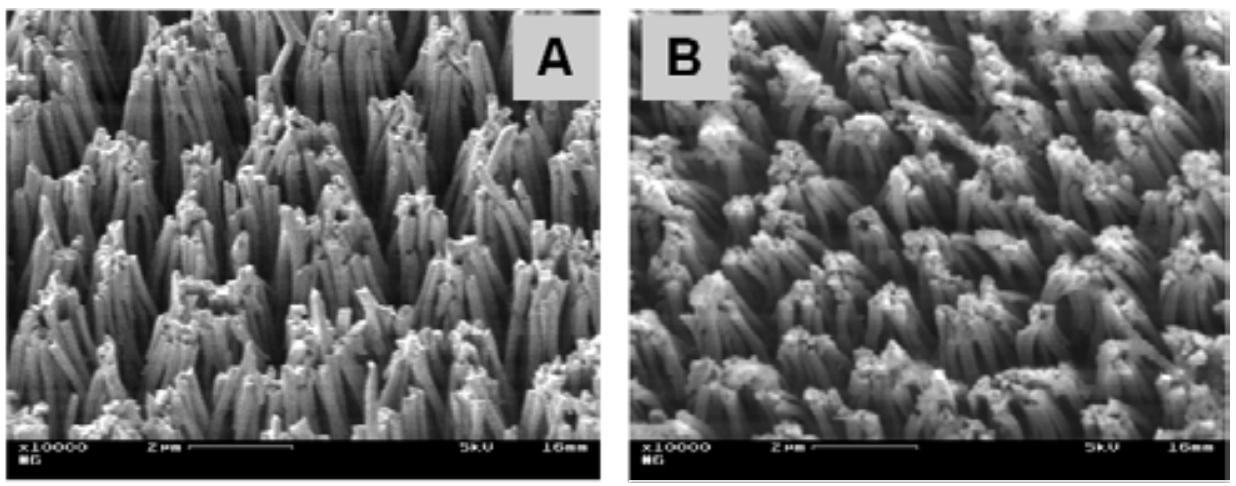

Fig. 3. 3D gold nanopillar (aspect ratio=30) structures developed using an aqueous based electrodeposition method: (A) as deposited, and (B) after water exposure.

The type of deformation shown in figure 3 is believed related to the high aspect ratio of these nanopillars. With an aspect ratio of 30, the bending resistance of the nanopillars will certainly be reduced. When silver nanopillar structures with an aspect ratio of 10 (Fig. 4A \& 4B) and gold nanopillar structures with an aspect ratio of 5 (Fig. 4C \& 4D) are tested, both cases show no bunching or clumping deformation in the nanopillars after water exposure (Fig. 4B \& 4D) as compared with before water exposure (Fig. 4A \& 4C). These results indicate that the nanopillar array structures developed using an aqueous electrodeposition method do possess sufficient mechanical robustness to resist the capillary interaction forces. Since the 3D skyscraper nanopillar presented above are made of different materials and with different diameters, it raises a question: will such differences affect the resistance of these nanopillars to capillary interaction? By considering a standing nanopillar as a cantilever beam with a point load ( $P$, representing the net equivalent capillary force) acting on it, the deflection of the nanopillar ( $\delta$ ) can be expressed as $\delta=P L^{3} / 3 E I$ (Beer et al., 2002), where $E$ is Young's modulus of the material, $L$ is the height of the nanopillar and $I$ is the second moment of inertia ( $I=\pi \cdot D^{4} / 64, D$ is the diameter of the nanopillar). Obviously, the diameter of the nanopillar will affect the bending rigidity. However, according to Kralchevsky et al. (2000) the capillary force generated at the nanopillar is proportional to the diameter of nanopillar as $P=K\left(\gamma, \varphi, d_{i}\right) \cdot D$, where $K\left(\gamma, \phi, d_{i}\right)$ is a function of physical conditions such as the surface tension $(\gamma)$, contact angle $(\phi)$ as well as the internanopillar distance $\left(d_{i}\right)$. Thus, the deflection of the nanopillar upon capillary interaction is proportional to the aspect ratio to the third power and is inversely related to the Young's modulus as $\delta \propto(L / D)^{3} / E$. Therefore, aside from these physical conditions, the aspect ratio of the nanopillars and their mechanical properties are important factors influencing the resistance of these nanopillars to capillary interaction. Since the values of the Young's modulus of amorphous silicon, gold and silver are very close: $80 \mathrm{GPa}$ for silicon (Freund et al., 2003), $78 \mathrm{GPa}$ for gold and $83 \mathrm{GPa}$ for silver (Gardner et al., 2002), only the physical conditions (the surface tension, contact angle and internanopillar distance) and the aspect ratio will have dominating effects on the resistance of these nanopillars to capillary interaction. 

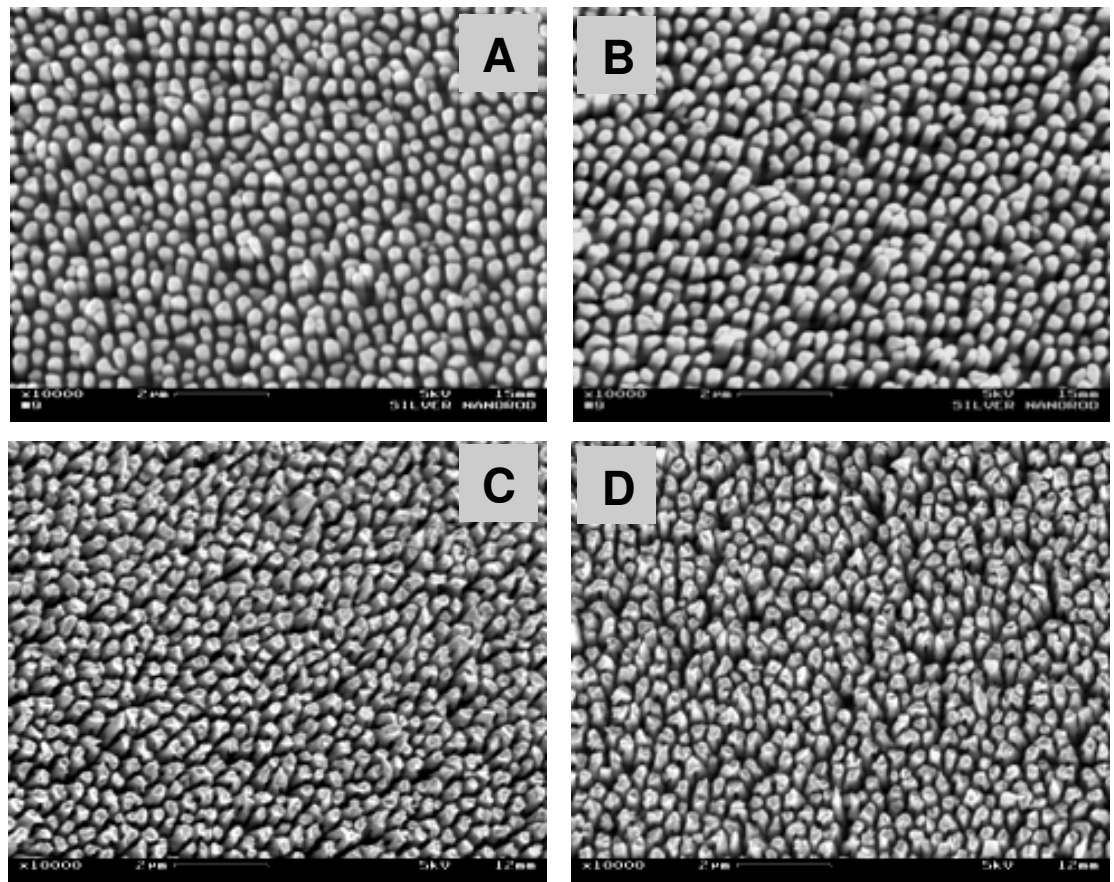

Fig. 4. 3D silver nanopillar (aspect ratio $=10)$ structures before $(A)$ and after $(B)$ water exposure and $3 \mathrm{D}$ gold nanopillar (aspect ratio $=5$ ) structures before $(C)$ and after $(D)$ water exposure.

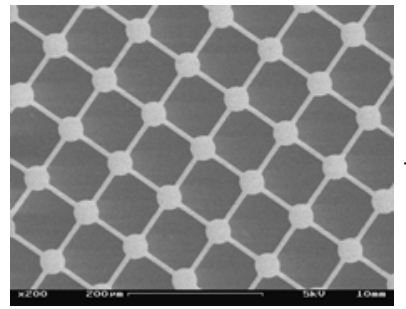

A network of connected micro dots

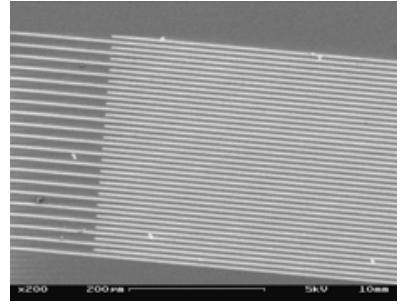

A pair of interdigitated electrodes

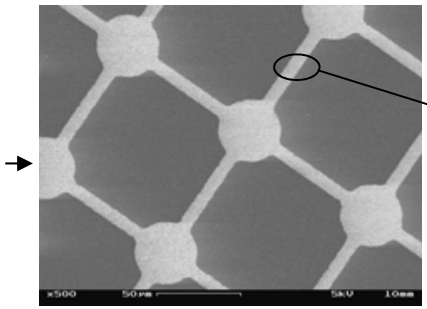

Zoom-in view

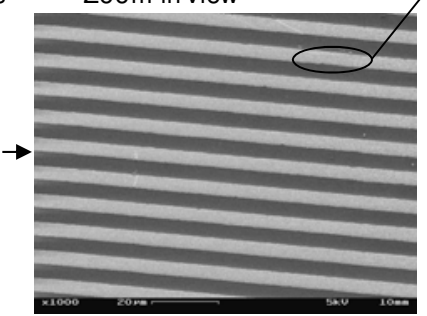

Zoom-in view

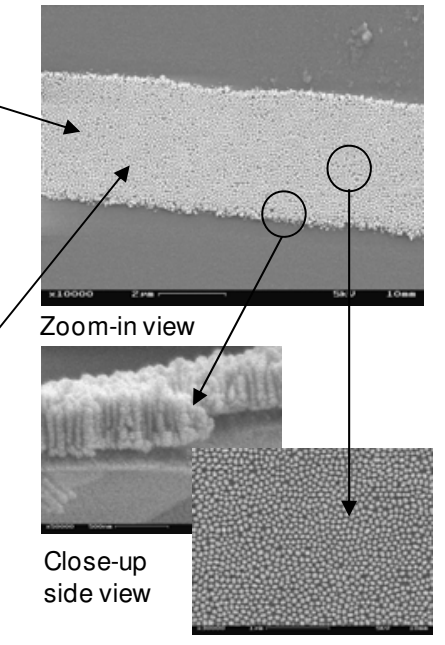

Close-up top view

Fig. 5. SEM images showing a micro scale structure (a network of connected microdots) and a device (a pair of interdigitated electrodes) fabricated out of 3D skyscraper nanopillar structures. 
Although robust, these 3D skyscraper nanostructures are formed on free-standing thin films. One drawback of such structures is that it is difficult to turn them into devices through further structural processing. To be able to process these 3D structures through conventional lithographical steps, it is ideal to have these 3D nanostructures formed on a supporting wafer substrate. To meet this need, we have developed a novel process to fabricate 3D skyscraper nanostructures on glass or wafer substrates (Zhang et al., 2008). In this process, multiple layers of metallic films (e.g., $5 \mathrm{~nm}$ Titanium layer, $10 \mathrm{~nm}$ Gold layer and $10 \mu \mathrm{m}$ Alumium layer) are first deposited onto the substrate. Then the top aluminum layer is anodized to form a porous Alumina template. After that, gold nanopillars are electrodeposited into the pores of the template. Finally, the porous alumia template is removed. With such nano structures formed on this surpporting substrate, we then pattern them into micro devices via conventional photolithographic processes. Figure 5 shows some examples of such integrated micro and nano structures on glass substrates: a network of connected micro dots and a pair of interdigitated electrodes fabricated out of 3D skyscraper nanopillar structures.

\section{Electrochemical characterization of 3D skyscraper nanostructures}

\subsection{Bare surfaces}

To characterize the 3D skyscraper nanostructures with bare surfaces, cyclic voltammetry (CV) analysis can be performed. To do that, the 3D nanostructures are used as working electrode in a three-electrode electrochemical cell. Figure 6 shows the CV curves for three nanopillar structures and a flat control structure measured in blank solution containing 0.3 $\mathrm{M}$ sulphuric acid as a supporting electrolyte. The inset in figure 6 shows the SEM images of a side-view of the three specimens. From these SEM images, it is estimated that the nanopillars in specimens A, B and C have a diameter of about $150.0 \mathrm{~nm}$ and a height approximately $1.0 \mu \mathrm{m}, 2.5 \mu \mathrm{m}$ and $6.0 \mu \mathrm{m}$, respectively.

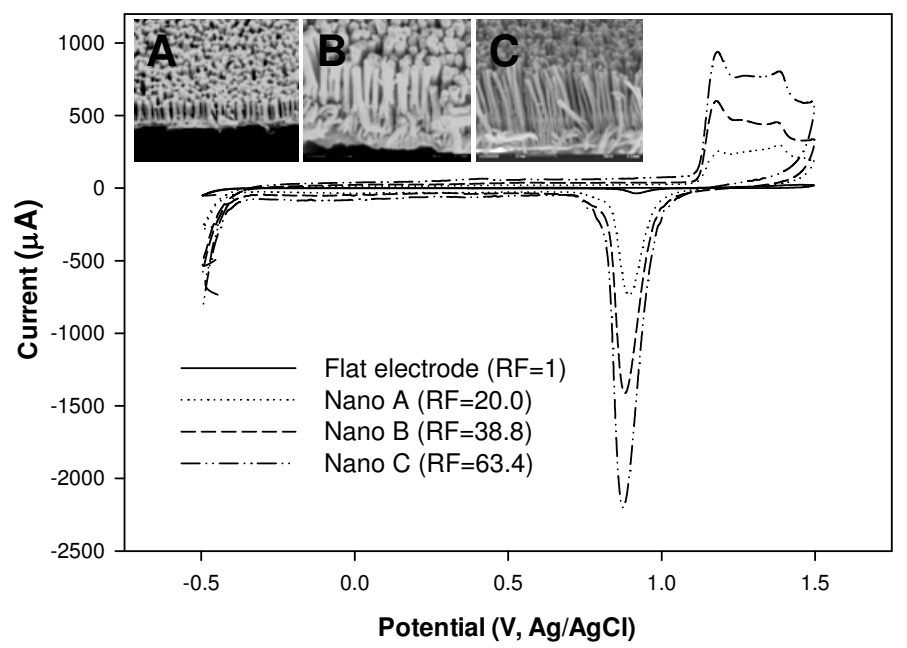

Fig. 6. CV curves for three 3D nanopillar structures and a flat structure with bare surfaces obtained in blank solution containing $0.3 \mathrm{M}$ sulphuric acid as a supporting electrolyte. The inset shows the SEM images of a side-view of the three specimens. 
All these CV curves show an Au-oxide reduction peak at around $0.85 \mathrm{~V}$, as expected. To quantify the difference in the height of the nanopillars in these 3D skyscraper structures, a roughness factor is determined as the area under the reduction peak of a nanopillar electrode divided by that of the flat electrode. The roughness factor (RF) for specimens A, B and $C$ is found to be 20.0,38.8 and 63.4, respectively.

When a redox couple, $\left[\mathrm{Fe}(\mathrm{CN})_{6}\right]^{4-} /\left[\mathrm{Fe}(\mathrm{CN})_{6}\right]^{3-}$, is used along with a supporting electrolyte, more structural characteristics can be revealed from the $\mathrm{CV}$ curves. Figure 7 shows the $\mathrm{CV}$ curves for a $3 \mathrm{D}$ and a flat gold structures measured in solution containing $0.5 \mathrm{M} \mathrm{Na}_{2} \mathrm{SO}_{4}$ as a supporting electrolyte and $4 \mathrm{mM} \mathrm{K}_{4} \mathrm{Fe}(\mathrm{CN})_{6}$ as a redox probe. The $\mathrm{CV}$ curves show that the redox peak current increases with increasing scan rate. Furthermore, the peak currents for the 3D nanopillar structures are much higher than those for the flat one. Here each CV curve represents 10 cycles of repeated measurements, suggesting that the 3D nanopillar structures are very stable with no further deformation or change in morphology during the electrochemical processes. If these nanopillars are not strong enough to overcome the capillary forces in such an aqueous environment, they will deform during the electrochemical processes, which will subsequently lead to decreased active surface area and hence decreased current output.
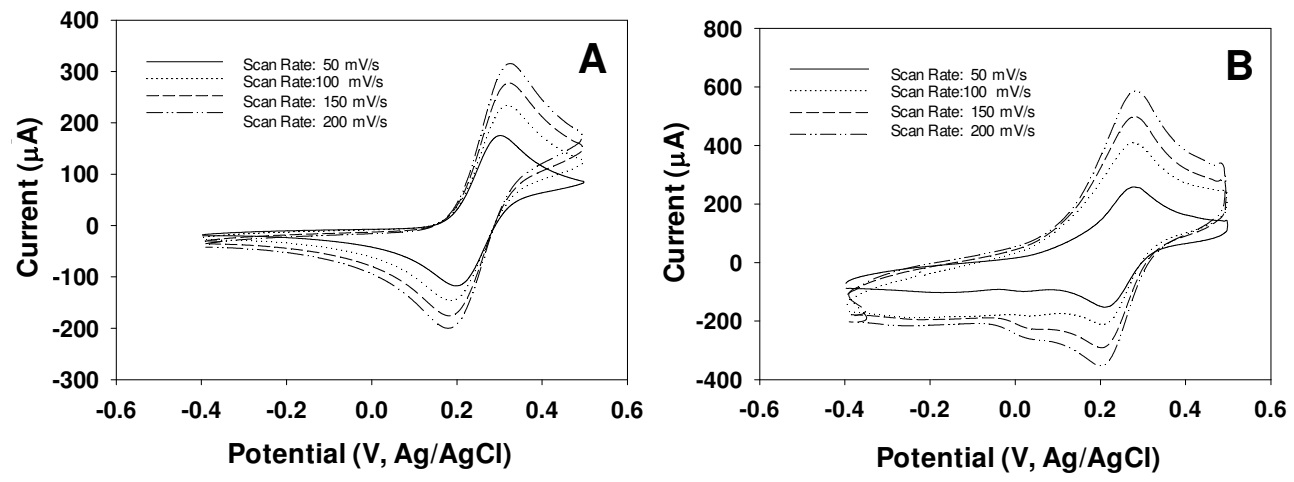

Fig. 7. CV curves for a gold flat (A) and 3D nanopillar (B) structures with bare surfaces obtained in solution containing $0.5 \mathrm{M} \mathrm{Na}_{2} \mathrm{SO}_{4}$ as a supporting electrolyte and $4 \mathrm{mM} \mathrm{K}_{4} \mathrm{Fe}(\mathrm{CN})_{6}$ as a redox probe.

From these CV curves, a peak separation $\Delta E_{p}=70 \mathrm{mV}$ is found for the 3D nanopillar structure, which is much closer to an ideal Nernstian behavior $\left(\Delta E_{p}=59 \mathrm{mV}\right)$ as compared with that for the flat structure $\left(\Delta E_{p}=110 \mathrm{mV}\right)$, indicating that electron transfer at the surface of the 3D nanopillar structures is significantly enhanced.

\subsection{SAM treated surfaces}

As discussed earlier, most of these 3D skyscraper nanostructures are made of inorganic materials, thus for applications as electrodes in biosensors they have to be functionalized for biological recognition purposes. Since most biosensitive molecules cannot be immobilized directly onto the surface of these inorganic materials, anchoring molecules such as self assembled monolayer (SAM) molecules are necessary. We have evaluated the formation of two SAM molecules, i.e., (1) 3-mercaptopropionic acid or MPA: HS- $\left(\mathrm{CH}_{2}\right)_{2}-\mathrm{COOH}$ and (2) 
11-mercaptoundecanoic acid or MUA: HS- $\left(\mathrm{CH}_{2}\right)_{10}-\mathrm{COOH}$ at the surface of these 3D nanopillar structures (Anandan et al., 2009). To treat the 3D nanopillar structures with the SAM molecules, the structures are immersed in ethanol solution containing $10 \mathrm{mM}$ of either the MPA or MUA molecules for 24 hours. SAM formation on these 3D structures is characterized by the $\mathrm{CV}$ and electrochemical impedance spectroscopy (EIS) techniques. The $\mathrm{CV}$ measurements are performed by scanning the potential from $-0.2 \mathrm{~V}$ to $0.6 \mathrm{~V}$ at a scan rate of $100 \mathrm{mV} / \mathrm{s}$ and the EIS measurements are performed in a frequency range from $0.1 \mathrm{~Hz}$ to $100 \mathrm{KHz}$ at a potential of $10 \mathrm{mV}$ in $0.1 \mathrm{M}$ phosphate buffered solution (PBS, pH7) containing $2 \mathrm{mM} \mathrm{Fe}(\mathrm{CN}) 6^{3-/ 4-}$ (ferri:ferro=1:1) mixture as a redox probe.

For assessing the percentage of defects in the SAM molecules, the voltammetric reduction peak associated with the uncovered area (i.e., the exposed gold oxide) in the SAM treated 3D structures is evaluated. The ratio of the uncovered area of a SAM treated 3D structure to that of a bare 3D structure is calculated and the percentage of defects in the SAM molecules is determined. To quantify the surface coverage $(\Gamma)$ of the SAM molecules, the method reported in the literature (Walczak et al., 1991; Sawaguchi et al., 2001; Ding et al., 2005) is used to evaluate the voltammetric reduction peak associated with SAM desorption. From the reduction peak, the amount of charge is determined by first integrating the reduction current under the peak over time and then offsetting the value by that of a bare 3D electrode. With the formula $\Gamma=\mathrm{Q} / \mathrm{nFA}$ (Walczak et al., 1991), in which $\mathrm{Q}$ is the amount of charge, $\mathrm{n}(=1)$ is the number of electrons involved in the reaction, $\mathrm{F}(=96485 \mathrm{C} / \mathrm{mol})$ is the Faraday constant and $\mathrm{A}\left(=0.04 \mathrm{~cm}^{2}\right)$ is the electroactive surface area, the surface coverage of SAM molecules is determined.
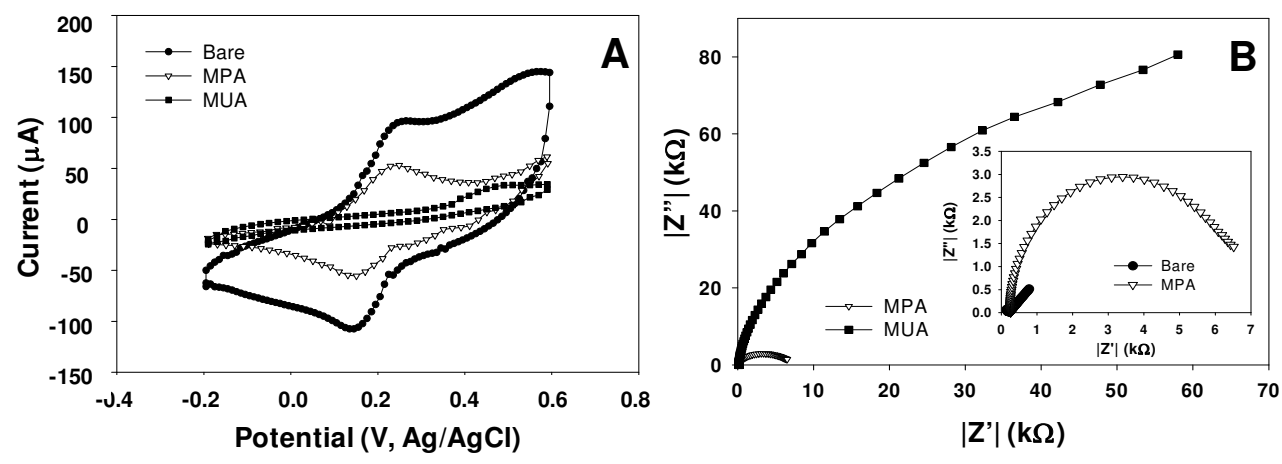

Fig. 8. (A) CV curves for a bare, MPA and MUA treated surfaces obtained in solution containing $\mathrm{H}_{2} \mathrm{SO}_{4}$ as a supporting electrolyte and $\left[\mathrm{Fe}(\mathrm{CN})^{6}\right]^{4-} /\left[\mathrm{Fe}(\mathrm{CN})^{6}\right]^{3-}$ as a redox probe at a scan rate of $100 \mathrm{mV} / \mathrm{s}$. (B) The corresponding Nyquist plots from the EIS measurements with a close-up view of the low impedance range given in the inset.

In figure 8A the $\mathrm{CV}$ curves obtained for a bare, MPA and MUA treated 3D structures evaluated in the presence of the redox couple $\left[\mathrm{Fe}(\mathrm{CN})_{6}\right]^{4-} /\left[\mathrm{Fe}(\mathrm{CN})_{6}\right]^{3-}$ are shown. In comparison between the bare and SAM treated structures, the bare one exhibits much higher redox peak currents. Between the two SAM treated structures, the MUA treated one exhibits lower redox peak currents than the MPA treated one, suggesting a higher degree of blockage for electron transfer resulting from the MUA molecules than from the MPA 
molecules. For both the bare and the MPA treated 3D structures the CV curves show a reversible redox event occurring at the surface with the electron transfer limited by diffusional mass transport. By contrast, the CV curves for the MUA treated structure exhibits highly irreversible redox behavior, confirming a high degree of blockage at the surface for electron transfer. Taken together, the above results indicate that both the MUA and MPA molecules form SAM structures covering the surface of the 3D nanopillar structures and that there are more MUA molecules than MPA molecules blocking the pathways for electron transfer across the electrode-electrolyte interface, owing possibly to the longer chain length of the MUA molecules forming more lateral molecular bonds.

Figure $8 \mathrm{~B}$ shows the corresponding impedance spectra (Nyquist plots) for these 3D structures. The two SAM treated structures show semicircular Nyquist plots whereas the bare one exhibits a straight line plot (see the lower inset plot in Fig. 8B). Since a semicircular feature is indicative of blockage for electron transfer across the electrode/electrolyte interface, this result confirms the formation of SAM molecules at the surfaces. Moreover, the MUA treated structure exhibits a larger semicircle than the MPA treated one, suggesting a high degree of SAM coverage for the MUA than for the MPA molecules. By using a Randles equivalent circuit to fit the obtained semicircular Nyquist plots, the resistance value for electron transfer $\left(R_{e t}\right)$ can be resolved. In this case, the $R_{\text {et }}$ value obtained for the MUA treated structure is 27 times higher than that for the MPA treated structure. This result confirms that the MUA molecules indeed post a higher electron transfer resistance at the electrode surface than the MPA molecules.

The CV curves obtained from the Au-oxide reduction experiments (figure 9A) exhibit an Au-oxide reduction peak at around $0.78 \mathrm{~V}$, indicating that all these $3 \mathrm{D}$ electrodes possess a certain amount of defects on the SAM treated surfaces. By the ratio of the area under the reduction peak (by integrating the $\mathrm{CV}$ curve under the peak) of the SAM treated $3 \mathrm{D}$ structure to that of the bare $3 \mathrm{D}$ structure, the percentage of defects is found to be approximately $87.3 \%$ and $37.8 \%$ for the MPA and MUA SAMs, respectively. These values are high when compared with flat structures: $52 \%$ for the MPA and $0 \%$ for the MUA SAMs (Campuzano et al., 2002).
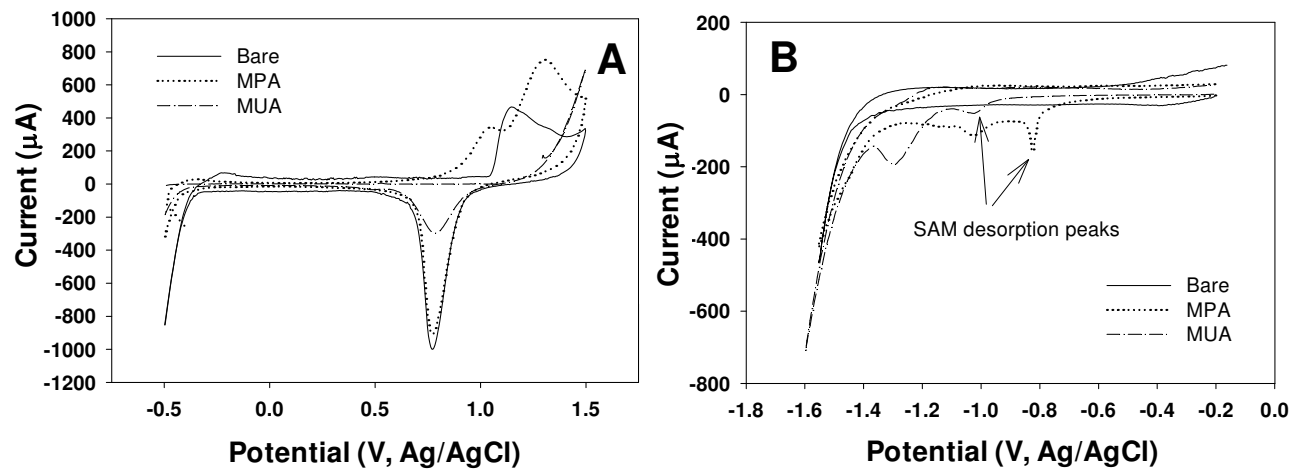

Fig. 9. (A) CV curves for a bare, MPA and MUA treated 3D structures obtained in quantifying the percentage of defects in SAM molecules in blank solution containing $0.1 \mathrm{M} \mathrm{H}_{2} \mathrm{SO}_{4}$ as a supporting electrolyte. (B) CV curves for the same structures obtained in evaluating SAM desorption in blank solution containing $0.1 \mathrm{M} \mathrm{NaOH}$ as a supporting electrolyte. 
Figure 9B shows the CV curves obtained for evaluating the voltammetric reduction peak associated with desorption of the MPA and MUA molecules. In the CV curves, two peak currents are visible for both the MPA and MUA treated 3D structures. The peak current at around $-0.82 \mathrm{~V}$ for the MPA and around $-1.03 \mathrm{~V}$ for the MUA are due to the cleavage of the gold-sulfur bond, according to the literature that a peak desorption current between -0.6 to $0.9 \mathrm{~V}$ is reported for short alkanethiols ( $\mathrm{n}=2$ to 6$)$ and between -1.0 to $-1.2 \mathrm{~V}$ for long alkanethiols ( $\mathrm{n}=11$ to 18) (Widrig et al., 1991; Imabayashi et al., 1997; Sawaguchi et al., 2001; Ding et al., 2005). Based on these desorption peak currents, the desorption charge is determined by integrating the reduction peak from $-0.8 \mathrm{~V}$ to $-0.9 \mathrm{~V}$ for the MPA treated structure and from $-1.0 \mathrm{~V}$ to $-1.2 \mathrm{~V}$ for the MUA treated structure. The surface coverage values are found to be $1.38 \times 10^{-8} \mathrm{~mol} / \mathrm{cm}^{2}$ and $2.37 \times 10^{-8} \mathrm{~mol} / \mathrm{cm}^{2}$ for the MPA and MUA treated electrodes respectively. Comparing with the reported values for the surface coverage for the MPA $\left(5.12 \times 10^{-10} \mathrm{~mol} / \mathrm{cm}^{2}\right)$ and the MUA $\left(8.30 \times 10^{-10} \mathrm{~mol} / \mathrm{cm}^{2}\right)$ on flat surfaces (Campuzano et al., 2002), the values for the 3D nanopillar structures are roughly 27 and 28 times higher. This increase can be attributed to the increase in the electroactive surface area in the 3D electrodes.

\subsection{Functionalized surfaces using SAM and avidin}

Since these SAM molecules only serve as an anchoring layer, functional molecules are still needed to make these 3D skyscraper nanostructures functionally sensitive to analyte targets. Many biological couples such as antibody-antigen, protein-ligand, protein-aptamer, pairednucleotides and avidin-biotin can be used for this purpose. Here we will discuss a case using the avidin-biotin couple as the biosensitive element for a biosensor. In using the avidin-biotin couple, one species, often avidin, has to be immobilized onto the active surface of the biosensor, and the other is usually tethered to a target molecule. As a demonstration, we will immobilize avidin and use biotin as the target.

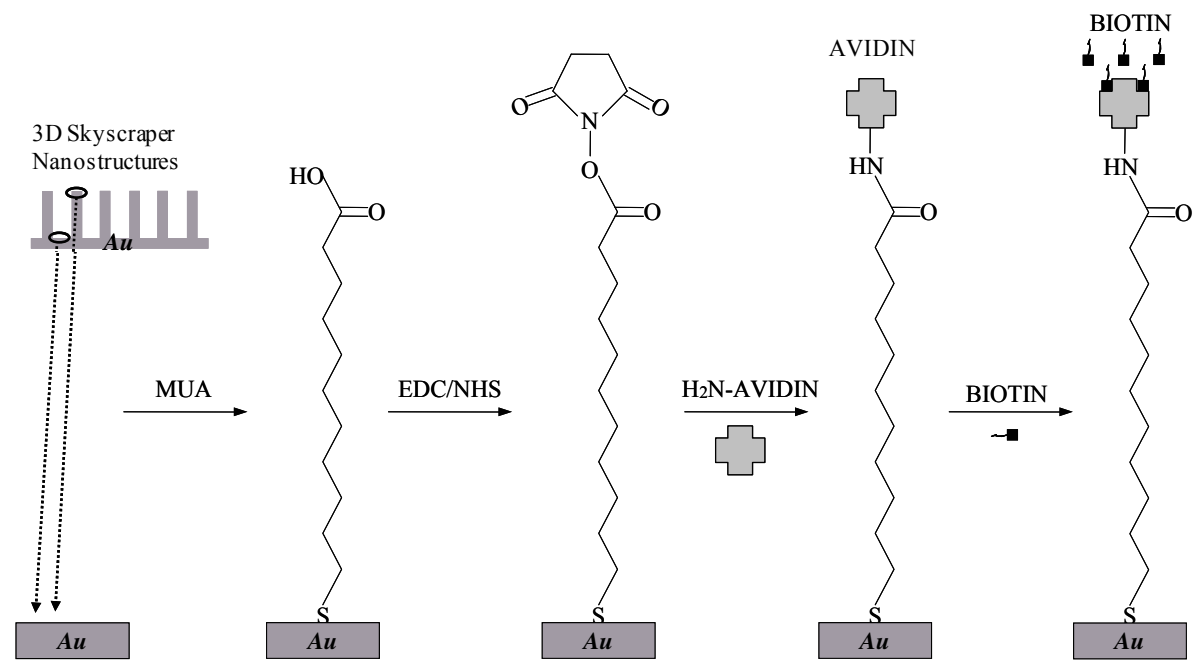

Fig. 10. Schematic illustration of a sequential procedure used to modify the surface of a 3D gold nanopillar structure. 
A SAM of anchoring MUA molecules is first formed at the surface of a 3D nanopillar structure. The MUA is then activated (i.e., turning the $\mathrm{COOH}$ groups into reactive N-hydroxysuccinimice esters) by immersing the structure in PBS containing $30 \mathrm{mM}$ 1-3-Dimethyl-amino-propyl-3-ethyl-carbodiimide hydrochloride and $15 \mathrm{mM}$ N-hydroxysuccin-imide for 3 hours at $25^{\circ} \mathrm{C}$. The 3D structure is then functionalized with avidin in PBS solution containing $300 \mu \mathrm{L}$ of avidin at $200 \mu \mathrm{g} / \mathrm{mL}$ for 2 hours at $25^{\circ} \mathrm{C}$. Figure 10 shows a schematic illustration of the stepwise procedures for the surface modification.

Figure 11A shows the CV measurements during the stepwise surface modification using MUA, avidin and biotin. Clearly, a bare 3D structure exhibits a peak-shaped CV curve, indicating a diffusion-controlled electrode process. Moreover, the CV curve has a peak-topeak separation measured at $\Delta E_{\mathrm{p}}=59.8 \mathrm{mV}$, which is very close to an ideal Nernstian oneelectron reaction having $\Delta E_{\mathrm{p}}=59 \mathrm{mV}$ (Bard et al., 2001). This fact suggests a highly efficient electron transfer mechanism across the electrode/electrolyte interface of the 3D nanopillar structure.

After the MUA layer is adsorbed to the electrode surface, the peak-shaped CV curve exhibits much reduced peak currents and increased peak-to-peak separation, suggesting blockage for electron transfer due to MUA adsorption. With more layers of molecular adsorption (i.e., avidin and biotin), the CV curve shows no obvious redox peaks. Instead, it looks more like a sigmoid having significant hysteresis between the forward and backward scans. This behavior implies that the electrons passing across the electrode/electrolyte interface are fulfilling two duties: to facilitate redox reaction and to charge the electrical double layer. Also, a lack of peak currents in these CV curves suggests that the adsorption of molecules to the surface has significantly lowered the electron transfer rate such that the electrode process is no longer controlled by a diffusion process as in the case of a bare electrode. Instead, it is now a kinetics-controlled process, meaning that it is limited by the rate of electron transfer.
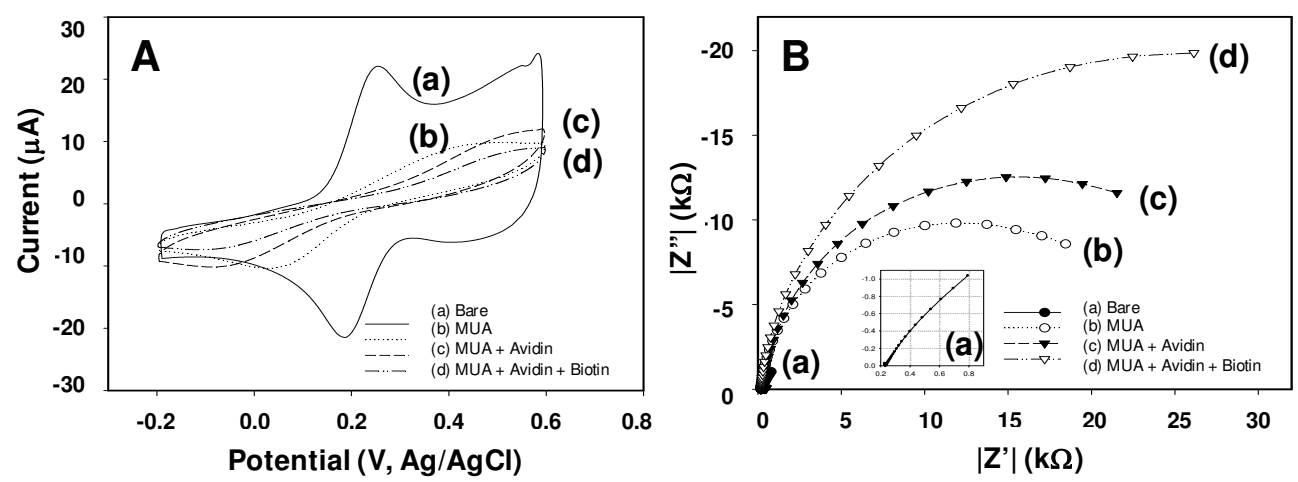

Fig. 11. (A) CV curves for examining the electrode/electrolyte interface during stepwise surface modification. (B) The corresponding Nyquist plots with a close view of the trace (a).

As shown in figure 11A, the peak current (or the limiting current) of these CV curves decreases as more layers of molecules are adsorbed to the surface. This is because the increase in the thickness of the adsorbed molecular layer at the surface has caused further reduction in electron transfer, thus slowing down the redox activity of $\left[\mathrm{Fe}(\mathrm{CN})_{6}\right]^{4-} /\left[\mathrm{Fe}(\mathrm{CN})_{6}\right]^{3-}$. 
The observed sequential change in the CV curve corresponds very well with the stepwise adsorption of MUA, avidin and biotin at the surface.

From the EIS measurements shown in figure 11B, it is seen that the Nyquist plot for the bare 3D structure (see inset) is nearly a straight line with its slope close to one. This fact confirms a diffusion-controlled electrode process occurring at the surface of the bare 3D structure. For the other cases, semicircular Nyquist impedance spectra are observed. The diameter of these Nyquist semicircles increases as the sequential adsorption of MUA, avidin and biotin proceeds at the surface. This fact indicates that the resistance to electron transfer at the electrode/electrolyte interface increases as more layers of molecules are added to the surface. Moreover, these Nyquist plots do not possess a linear part at low frequency, confirming that after the adsorption of various molecules the electrode process is no longer a diffusion-controlled process but a kinetics-controlled one.

\subsection{Functionalized surfaces using PPy and GOx}

In many biosensors, the functionalization of electrodes made of 3D skyscraper structures is often aimed at a specific target. In a glucose biosensor, for example, its electrode should be reactive to glucose. Very often, glucose specific enzyme - glucose oxidase (GOx) - is immobilized onto the surface of the electrode with the use of anchoring molecules such as SAM molecules. One drawback of using SAM molecules is that they always get in the way of electron transfer across the electrode/electrolyte interface as demonstrated in section 4.3 (see figure 11), thus affecting the detection performances. In contrast, physical entrapment of GOx in a porous polymer film near the electrode surface offers an attractive alternative. Conducting polymer like polypyrrole (PPy) can be electro- polymerized and deposited onto electrode surfaces to form a porous film, providing pores large enough for efficient electron transfer. Thus by mixing GOx in pyrrole solution, a porous polymeric film with GOx entrapped inside can be formed at the electrode surface via electrodeposition.
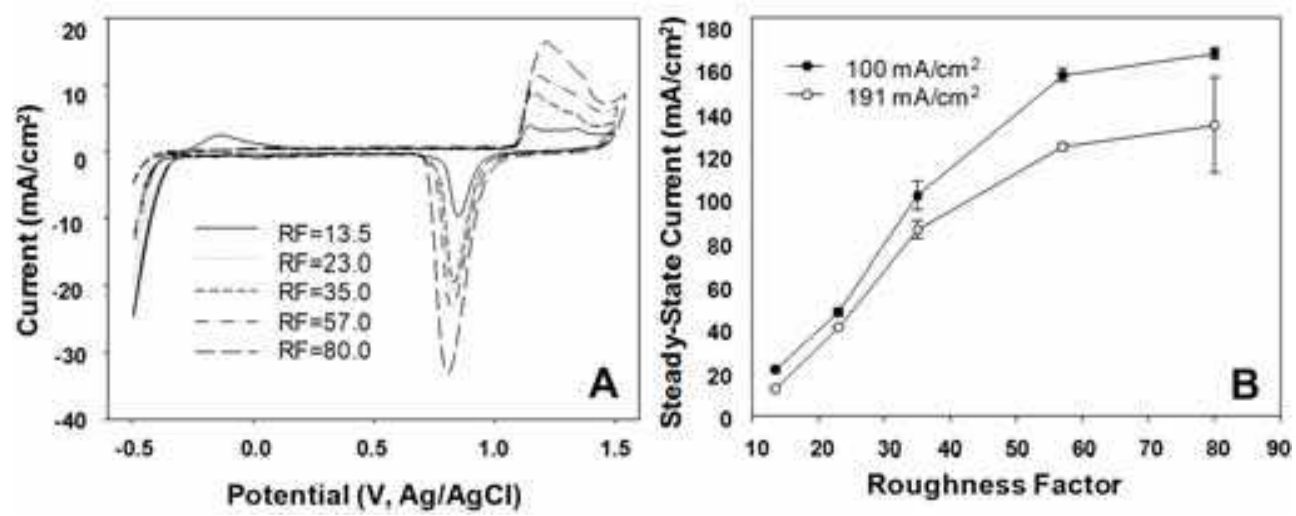

Fig. 12. (A) CV curves for five 3D nanopillar structures with different roughness factors obtained in blank solution containing $0.5 \mathrm{M} \mathrm{H}_{2} \mathrm{SO}_{4}$ as a supporting electrolyte. (B) Variation of amperometric steady-state current with roughness factor in response to glucose for the five 3D electrodes. Note $\mathrm{N}=3$ for each data point.

We have applied the functionalization procedure using PPy and GOx to 3D skyscraper nanopillar structures and investigated the effect of various parameters, such as the height of 
nanopillars, the electrodeposition current and the total charge passed, on the performance of the $3 \mathrm{D}$ electrodes in glucose detection. Figure 12A shows the CV curves obtained in blank solution containing $0.5 \mathrm{M} \mathrm{H}_{2} \mathrm{SO}_{4}$ for five $3 \mathrm{D}$ structures with different nanopillar heights. All the CV curves exhibit an Au-oxide reduction peak at around 0.85 V. From these reduction peaks, the roughness factor for the five 3D structures is found ranging from 13.5, 23.0, 35.0 and 57.0 to 80.0 .

Figure 12B shows the amperometric steady-state current in response to glucose at a fixed concentration of $4 \mathrm{mM}$ for the five 3D structures functionalized at two deposition currents $\left(100 \mu \mathrm{A} / \mathrm{cm}^{2}\right.$ and $\left.191 \mu \mathrm{A} / \mathrm{cm}^{2}\right)$ with the total charge set at $150 \mathrm{mC} / \mathrm{cm}^{2}$. Clearly, the steadystate current increases as the roughness factor increases and it appears to saturate when the roughness factor goes beyond 57 . The same phenomenon is seen for both current cases. This current-saturation behavior at a higher roughness factor is believed due to the difficulty encountered by glucose in diffusing down to the sides and roots of the nanopillars for oxidation as the height of the nanopillars reaches a certain level. This result is consistent with our previous observation (Anandan et al., 2007), and it may suggest that for glucose detection using the present method it is not necessarily beneficial to have 3D structures with nanopillars that are too tall. Figure 12B also shows that the steady-state current for the structures functionalized under a lower deposition current is higher than that under a higher deposition current, owing to a more uniform thickness for the PPy/GOx film formed under a lower deposition current.

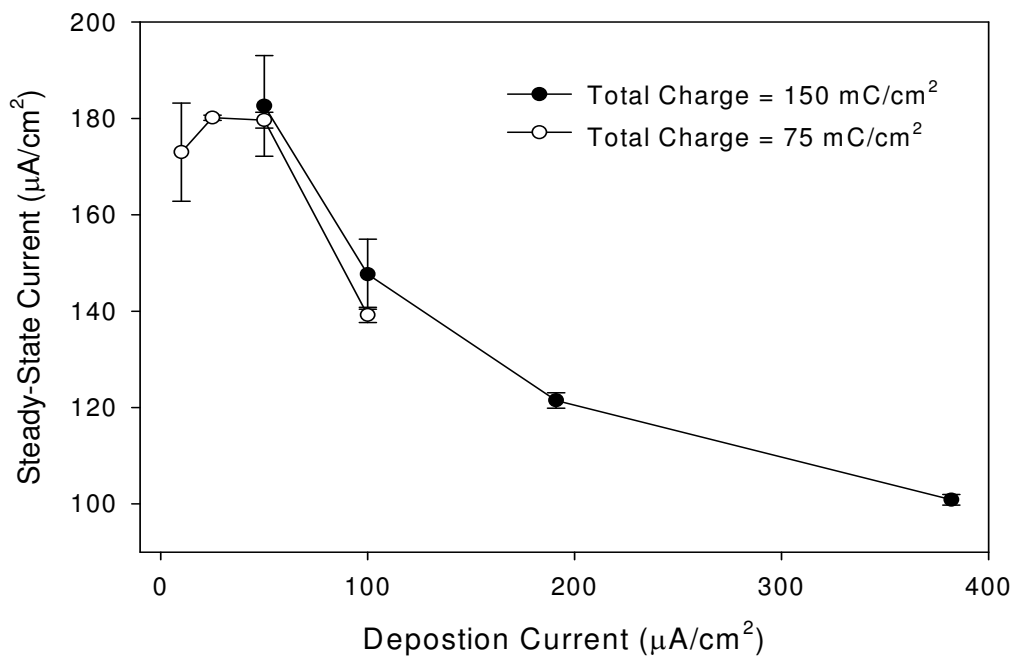

Fig. 13. Variation of the amperometric steady-state current with deposition current obtained under two different total charges. Note $\mathrm{N}=3$ for each data point.

Figure 13 shows the variation of stead-state current with deposition current for 3D structures with a roughness factor around 60 . At a total charge of $150 \mathrm{mC} / \mathrm{cm}^{2}$ the steadystate current increases as the deposition current decreases but with no obvious peak current performance within the range of the applied deposition currents (i.e., from 50 to 573 $\mu \mathrm{A} / \mathrm{cm}^{2}$ ). When the deposition current is lowered below $50 \mu \mathrm{A} / \mathrm{cm}^{2}$ (achieved at a reduced total charge of $\left.75 \mathrm{mC} / \mathrm{cm}^{2}\right)$ it became obvious that the steady-state current reached at the 
deposition current of $50 \mu \mathrm{A} / \mathrm{cm}^{2}$ is a peak value. From the overlap region of the two curves it is seen that these two curves are not only very close to each (the one under a lower charge density is slightly lower than the one under a higher charge density, as expected) but also following the same varying trend. Based on these results, the deposition current of 50 $\mu \mathrm{A} / \mathrm{cm}^{2}$ is deemed as an optimal value, which is quite different from that obtained for flat electrodes $\left(382 \mu \mathrm{A} / \mathrm{cm}^{2}\right)$.

This difference is attributed to the presence of the nanopillars. Because of these closely packed skyscraper nanopillars, the mass transport of the electroactive species (including pyrrole during electrodeposition and glucose during detection) to and from the functionalized surface will be different from the case without nanopillars. This is evident from the SEM images. Under a lower deposition current of $50 \mu \mathrm{A} / \mathrm{cm}^{2}$ all nanopillars are covered with a thin uniform layer of PPy/GOx (see Fig.14A). However, under a higher deposition current of $573 \mu \mathrm{A} / \mathrm{cm}^{2}$, the space between nanopillars close to the tips is all clogged up by the PPy/GOx (Fig.14B). This thick film formed under high deposition currents will surely pose a diffusion barrier for glucose, thus leading to low current responses (Fortier et al., 1990). Therefore, in the presence of closely packed skyscraper nanopillars, a much lower deposition current (e.g., $50 \mu \mathrm{A} / \mathrm{cm}^{2}$ instead of $382 \mu \mathrm{A} / \mathrm{cm}^{2}$ ) is necessary for forming a uniform functionalization layer at the surface of these 3D nanopillar structures.
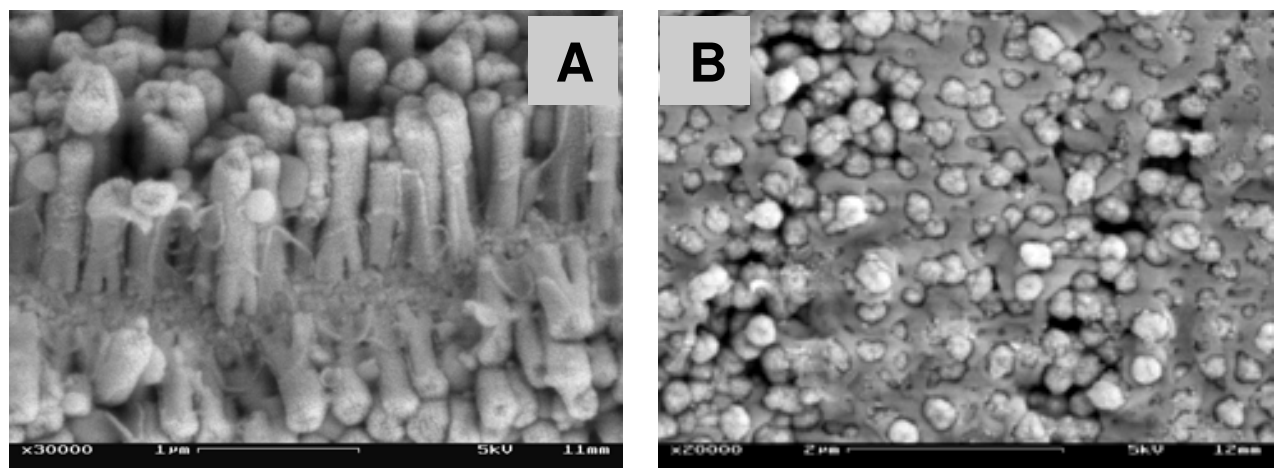

Fig. 14. SEM images of 3D nanopillar structures functionalized with PPy/GOx through an electrodeposition process when the total charge is controlled at $150 \mathrm{mC} / \mathrm{cm}^{2}$ under a deposition current of $50 \mu \mathrm{A} / \mathrm{cm}^{2}(\mathrm{~A})$ and $573 \mu \mathrm{A} / \mathrm{cm}^{2}(\mathrm{~B})$.

Figure 15A shows the variation of steady-state current with total charge measured in response to glucose for the 3D nanopillar structures (with a roughness factor around 60) functionalized at a fixed deposition current of $50 \mu \mathrm{A} / \mathrm{cm}^{2}$. As the total charge increases from 50 to $600 \mathrm{mC} / \mathrm{cm}^{2}$, the steady-state current increases a little bit in the beginning and then decreases after reaching a peak value at $150 \mathrm{mC} / \mathrm{cm}^{2}$. Figure $15 \mathrm{~B}$ shows the steady-state currents for the 3D nanopillar structures measured in response to ascorbic acid. Ascorbic acid, uric acid and acetaminophen are the common electroactive species coexisting in blood, and they tend to affect the accuracy of a glucose sensor (Cho et al., 1996). Thus for a better performance, a glucose sensor should have negligible responses to these nonspecific species. In general, ascorbic acid is considered as a representing endogenous interfering agent (Moatti et al., 1992), thus for this reason we choose ascorbic acid as a representative interfering species. These results show that the interference also reaches a peak value at a 
total charge of $150 \mathrm{mC} / \mathrm{cm}^{2}$. But the current value in response to ascorbic acid is much lower $\left(14.3 \mu \mathrm{A} / \mathrm{cm}^{2}\right)$ than that to glucose $\left(138.3 \mu \mathrm{A} / \mathrm{cm}^{2}\right)$. With a signal-to-noise ratio of about 9.7, the specificity of the functionalized $3 \mathrm{D}$ nanopillar structures to glucose is considered to be reasonably good.
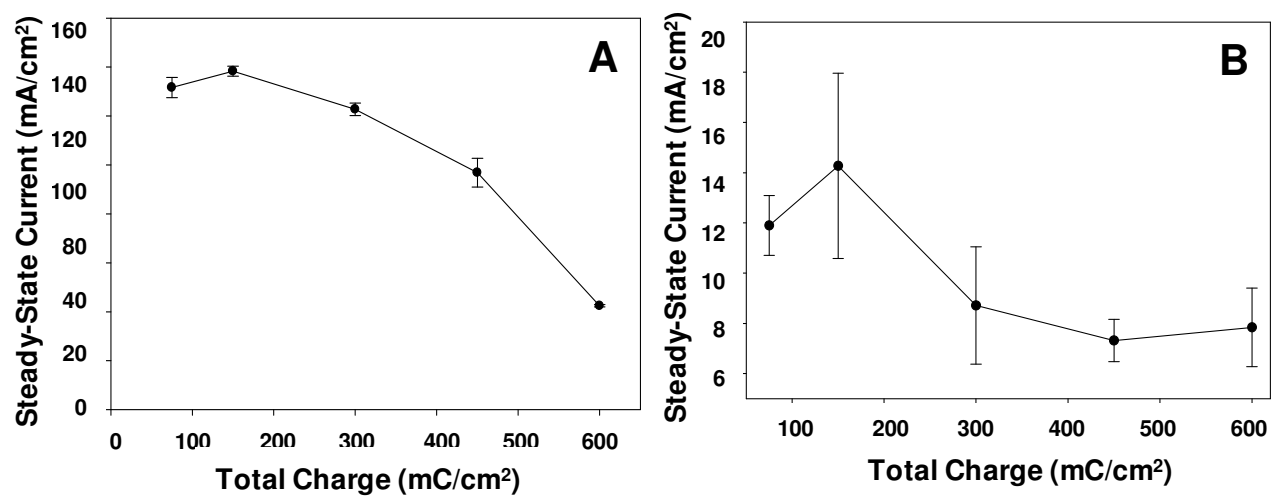

Fig. 15. Variation of amperometric steady-state current with total charge obtained for the functionalized 3D nanopillar structures (under a deposition current of $50 \mu \mathrm{A} / \mathrm{cm}^{2}$ ) in response to glucose (A) and to ascorbic acid (B). Note $\mathrm{N}=3$ for each data point.

Based on these results we believe that an electro-process with a deposition current of 50 $\mu \mathrm{A} / \mathrm{cm}^{2}$ and a total charge of $150 \mathrm{mC} / \mathrm{cm}^{2}$ will provide an optimal condition for functionalizing the 3D nanopillar structures using PPy/GOx. These electro-processing parameters are quite different from those obtained for the flat electrodes (Uang et al., 2002), and it can be attributed to the added surface area provided by the cylindrical walls of the nanopillars as well as the added difficulty for the active species in reaching the tiny space between these nanopillars (Anandan et al., 2007).

\section{Application of 3D skyscraper nanostructures as electrodes in biosensors}

Now let us compare the two functionalization methods by examining the detection sensitivity when these functionalized 3D nanopillar structures are used as electrodes for glucose detection. In the first case, the 3D nanopillar structures functionalized with SAM and GOx (in which GOx is tethered to the SAM) are used as electrodes, and in the second case the 3D nanopillar structures functionalized with PPy and GOx (in which GOx is entrapped in a porous film of PPy) are used as electrodes. In both cases, the amperometric steady-state current responses of these functionalized electrodes are measured in response to glucose at different concentrations. With the amperometric measurements, the relationship between the steady-state current and glucose concentration is calibrated in each case. From the calibration curves the detection sensitivity of the 3D nanopillar electrodes functionalized with two different methods is evaluated and compared.

\subsection{Electrode reactions in Gox catalyzed glucose detection}

For GOx catalyzed glucose detection, glucose first reacts with GOx to form gluconic acid and reduced-GOx. The reduced-GOx will then be converted back to its original form by 
reacting with p-benzoquinone $(\mathrm{BQ})$, a mediator having better solubility than most other popular mediators (Cooper et al., 1993). In a cascade of electrode reactions, the mediator gets reduced and then converted back to its original state at the electrode surface by giving away electrons. Figure 16 shows a cascade of events occurring in a mediator based glucose detection scheme.

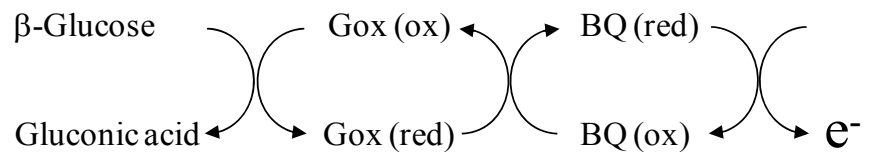

Fig. 16. A cascade of events in a mediator-based glucose detection scheme.

\subsection{Glucose detection using electrodes functionalized with SAM and GOx}

By using 3D nanopillar structures treated first with a SAM of MPA molecules followed by GOx as electrodes, amperometric measurements are made in PBS containing $3 \mathrm{mM}$ pbenzoquinone and certain amount of glucose at a constant electrode potential of $0.35 \mathrm{~V}$ (vs. $\mathrm{Ag} / \mathrm{AgCl}$ ). During amperometric experiment, the solution is stirred constantly for ensuring instant equilibrium for mass transport. During each test run, the background current is allowed to stabilize before a drop of glucose is added to the solution. After the amperometric current response reaches a steady-state, another drop of glucose is added and the corresponding current response is measured until a new steady state is reached. In this experiment each incremental drop of glucose is controlled to cause an equivalent increase in glucose concentration of approximately $2.5 \mathrm{mM}$.
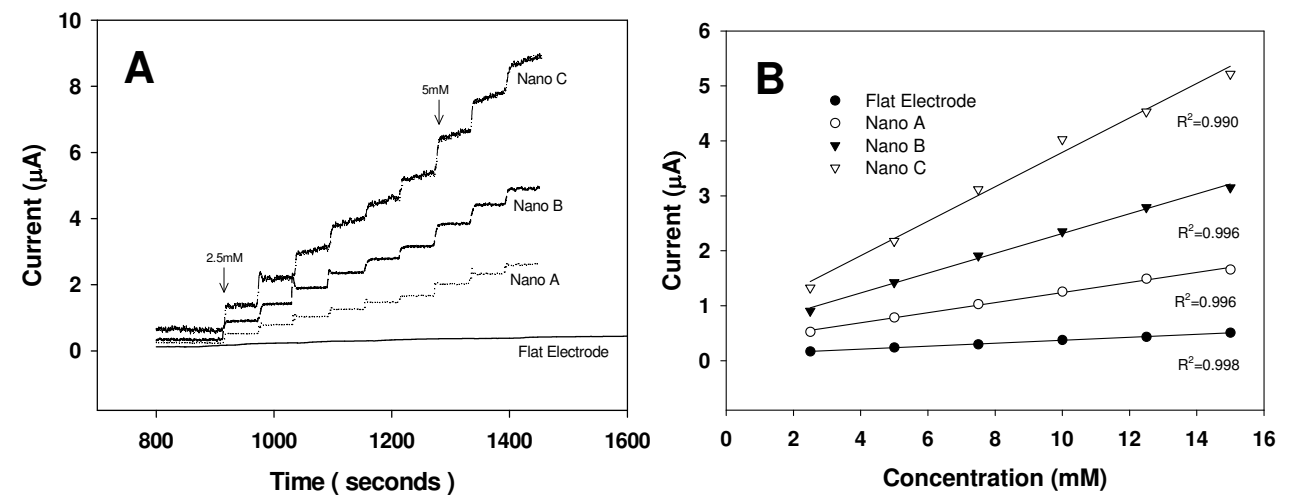

Fig. 17. (A) Amperometric current responses obtained for 3D electrodes functionalized with SAM and GOx when incremental drops of glucose are added to the solution. (B) Calibration curves along with linear-regression analyses for the relationship between the steady-state current and glucose concentration (from $2.5 \mathrm{mM}$ to $15 \mathrm{mM}$ ).

Figure 17A shows the amperometric current responses for three 3D nanopillar electrodes and a flat control electrode functionalized with MPA SAM and GOx. These three 3D electrodes have different surface roughness factors as characterized in figure 6. All three electrodes exhibit a higher current response than the flat control case at each glucose level. Figure 17B shows the variations of steady-state current with glucose concentration (from 
$2.5 \mathrm{mM}$ to $15 \mathrm{mM}$ ) along with the corresponding linear regression lines. By taking the slope of each regression line and normalizing it with respect to the geometric area of the electrode in each case, the sensitivity measurement for the functionalized electrodes is evaluated. In this case, the highest sensitivity value is found as $3.13 \mu \mathrm{A} \cdot \mathrm{mM}^{-1} \cdot \mathrm{cm}^{-2}$ (for specimen C) which is about 12 times higher than that of the flat electrode. This sensitivity value is much higher than the value reported for a gold nanotube electrode $\left(0.4 \mu \mathrm{A} \cdot \mathrm{mM}^{-1} \cdot \mathrm{cm}^{-2}\right.$, Delvaux et al., 2003).

\subsection{Glucose detection using electrodes functionalized with PPy and GOx}

By using 3D nanopillar structures coated with a mixture of PPy and GOx as electrodes, amperometric measurements are made under the same conditions as described in section 5.2. Figure 18 shows some measurements of the amperometric current responses when the concentration of glucose is increased in an increment of $2.5 \mathrm{mM}$. By taking the steady-state current at each glucose level, a scatter plot calibrating the relationship between the steadystate current and the glucose concentration is made. As shown in the inset in figure 18, the calibration curve shows a fairly good linear relationship $\left(\mathrm{R}^{2}=0.9998\right)$ between the steadystate current and glucose concentration in a glucose concentration range from 2.5 to $15 \mathrm{mM}$. Based on the slope of this calibration curve, the sensitivity value is determined as 36 $\mu \mathrm{A} \cdot \mathrm{mM}^{-1} \cdot \mathrm{cm}^{-2}$. This value is about twelve times higher than that in the case presented in section 5.2. This sensitivity value is the highest ever achieved for gold electrodes functionalized with PPy and GOx.

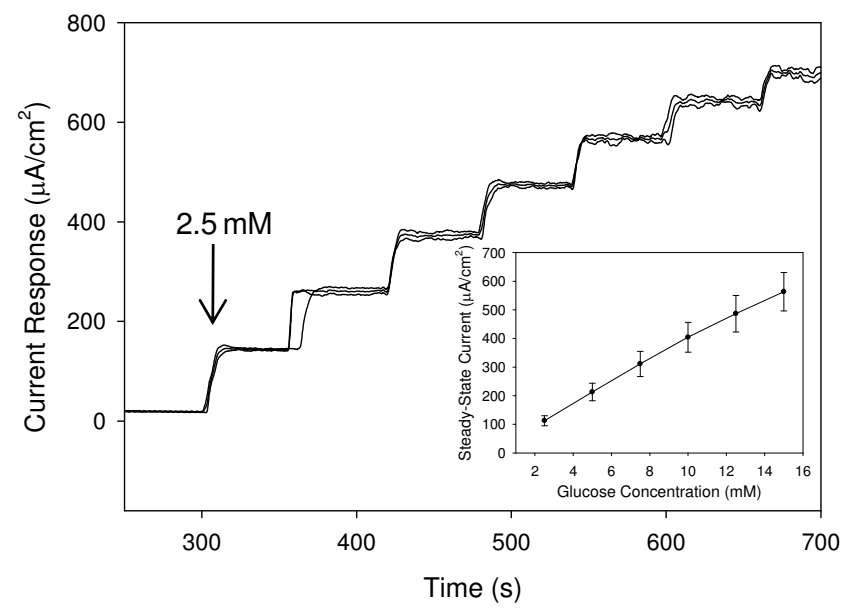

Fig. 18. Amperometric current responses to successive addition of glucose in the amount of $2.5 \mathrm{mM}$. The insert shows the calibration curve for the relationship between the steady-state current and glucose concentration.

\section{Conclusion and future perspective}

Nanotechnology holds great promises for improving the performance of many biosensors. In this chapter, we have domenstrated that the use of 3D electrodes having skyscraper nanopillar structures as electrodes in biosensors can drastically improve the sensitivity of glucose biosensors as compared with the use of flat electrodes. Of course, such 
improvement can only be achieved when the 3D skyscraper nanostructures are robust to overcome the capillary forces encountered in various solid-liquid interactions. The 3D skyscraper nanopillar structures fabricated by the electrodeposition technique described in this chapter have sufficient mechanical robustness to resist the capillary interaction forces.

To utilize these 3D nano structures in various fluidic systems, we have developed a novel process to fabricate 3D skyscraper nanostructures on wafer substrates. This development allows the formed 3D nano structures to be further processed through conventional lithographical steps such that they can be easily incorporated into various micro devices.

In addition to the 3D skyscraper morphological design, the sensing performance of these inorganic-based nanopillar electrodes is also affected by the type of functionalization methods used. For example, the 3D nanopillar electrodes functionalized with MPA SAM and GOx showed a detection sensitivity value of $3.13 \mu \mathrm{A} \cdot \mathrm{mM}^{-1} \cdot \mathrm{cm}^{-2}$, which is about 12 times higher than that for a flat electrode. By contrast, the 3D nanopillar electrodes functionalized with PPy and GOx exhibited an even higher sensitivity value of $36 \mu \mathrm{A} \cdot \mathrm{mM}^{-1} \cdot \mathrm{cm}^{-2}$. This fact suggests that using physical entrapment of GOx near the 3D electrode surface within porous PPy indeed provides an efficient means for electron transfer. In comparison, using a uniform layer of short chain SAM (i.e., the MPA) to tether GOx may still post a barrier to electron transfer across the electrode/electrolyte interface thus lowering the detection performance.

In the coming years it is anticipated that nanotechnology based biosensors will continue to evolve and expand their use in many areas of biological, pharmaceutical and biomedical concerns. These biosensors are expected to possess some ideal features such as high sensitivity, high specificity, fast response, low detection-limit, continuous and long-term functionality, and passively operational. As for the use of 3D nano structured electrodes in fluidic sensors, further efforts are needed in optimizing the geometric parameters of the 3D nano structures in terms of fluidic flow rates and channel geometries and dimensions.

\section{Acknowledgement}

I would like to thank my students V. Anandan, Y.L. Rao, R. Gangadharan and postdoctoral fellow S.J. Lee for their contributions to the work discussed here and the financial supports from the National Science Foundation, the Faculty of Engineering at the University of Georgia, and the Institute for Biological Interfaces of Engineering at Clemson University.

\section{References}

Anandan V, Gangadharan R, and Zhang G. (2009) The role of SAM chain length in enhancing the sensitivity of nanopillar modified electrodes for glucose detection. Sensors, 9(3): 1295-1305.

Anandan V, Yang X, Kim E, Rao Y and Zhang G (2007) Role of reaction kinetics and mass transport in glucose sensing with nanopillar array electrodes. Journal of Biological Engineering. 1, 1, 5 .

Anandan V, Rao YL. and Zhang G. (2006) Nanopillar array structures for high performance electrochemical sensing. International journal of nanomedicine. 1, 73 - 79.

Bard AJ and Faulkner LR. (2001) Electrochemical Methods: Fundamentals and Applications. 2nd Edition, John Wiley \& Sons, New York. 
Beer FP, Johnston ER, Deworf JT. (2002) Mechanism of materials. McGraw-Hill. $3^{\text {rd }}$ edition.

Berchmans S, Sathyajith R, Yegnaraman V. (2003) Layer-by-layer assembly of 1,4-diaminoanthraquinone and glucose oxidase. Materials Chemistry and Physics. 77: 390-396.

Bharathi S, Nogami M. (2001) A glucose biosensor based on electrodeposited biocomposites of gold nanoparticles and glucose oxidase enzyme. Analyst. 126, 1919-1922.

Campuzano, S.; Galvez, R.; Pedrero, M.; de Villena, F.J.M.; Pingarron, J.M. (2002) Preparation, characterization and application of alkanethiol self-assembled monolayer modified with tetrathiafulvalene and glucose oxidase at a gold disk electrode. d Electroanal. Chem. 526(1-2), 92-100.

Cho JH, Shin MC, Kim HS. (1996) Electrochemical adsorption of glucose oxidase onto polypyrrole film for the construction of a glucose biosensor Sensors and Actuators B: Chemical 30(2) 137-141.

Cooper JC, Hall EAH. (1993) Catalytic reduction of benzoquinone at polyaniline and polyaniline enzyme films. Electroanal. 5(5-6), 385-397.

Delvaux M, Demoustier-Champagne S. (2003) Immobilisation of glucose oxidase within metallic nanotubes arrays for application to enzyme biosensors. Biosensors \& Bioelectronics 18: 943-951.

Ding SJ, Chang BW, Wu CC, Lai MF, Chang HC. (2005) Impedance spectral studies of self-assembly of alkanethiols with different chain lengths using different immobilization strategies on Au electrodes. Anal. Chim. Acta. 554(1-2), 43-51.

Fan JG, Dyer D, Zhang G, Zhao Y. (2004) Nanocarpet effect: pattern formation during wetting of vertically aligned nanorod arrays. Nanoletters. 4, 2133-2138.

Forrer P, Schlottig F, Siegenthaler H. (2000) Electrochemical preparation and surface properties of gold nanowire array formed by template technique. I Appl. Electrochem. 30, 533-541.

Fortier G, Brassard E, and Bélanger D. (1990) Optimization of a polypyrrole glucose oxidase biosensor Biosensors and Bioelectronics 5(6) 473-490.

Freund LB, Suresh S. (2003) Thin Film Materials. Cambridge University Academic Press.

Gangadharan R, Anandan V, Zhang G. (2008) Optimizing the functionalization process for nanopillar enhanced electrodes with GOx/PPY for glucose detection. Nanotechnology. $19,395501$.

Gao M, Gordon LD, Dai L, Wallace G. (2003) Biosensor based on vertically aligned carbon nanotubes coated with inherently conducting polymers. Electroanalysis. 15, 13, 10891094.

Gardner JW, Varadan VK, Awadelkarim OO. (2002) Microsensors MEMS and smart deices. New York. Wiley.

Gooding JJ, Erokhin P, Hibbert DB. (2000) Parameters important in tuning the response of monolayer enzyme electrodes fabricated using self-assembled monolayers of alkanethiols. Biosensors \& Bioelectronics. 15: 229-239.

Gooding JJ, Praig VG, Hall EAH. (1998) Platinum-catalyzed enzyme electrodes immobilized on gold using self-assembled layers. Analytical Chemistry. 70: 2396-2402.

Gooding JJ, Erokhin P, Losic D, Yang W, Policarpio V, Liu J, Ho F, Situmorang M, Hibbert DB, Shapter JG. (2001) Parameters important in fabricating enzyme electrodes using self-assembled monolayers of alkanethiols. Analytical Science. 17: 3-9. 
Hou Y, Helali S, Zhang A, Nicole JR, Martelet C, Minic C, Gorojankina T, Persuy MA, Edith PA, Salesse R, Bessueille F, Samitier J, Errachid A, Akimov V, Reggiani L, Pennetta C, Alfinito E. (2006) Biosensors and Bioelectronics. 21, 1393-1402.

Hou Y, Nicole JR, Martelet C, Zhang A, Jasmina MV, Gorojankina T, Persuy MA, Edith PA, Salesse R, Akimov V, Reggiani L, Pennetta C, Alfinito E, Ruiz O, Gomila G, Samitier J, Errachid A. (2007) Biosensors and Bioelectronics. 22, 1550-1555.

Imabayashi S, Iida M, Hobara D, Feng ZQ, Niki K, Kakiuchi T. (1997) Reductive desorption of carboxylic-acid-terminated alkanethiol monolayers from $\mathrm{Au}(111)$ surfaces. $I$ Electroanal. Chem. 428, 33-38.

Jia F, Yu C, Ai Z and Zhang L. (2007) Fabrication of Nanoporous Gold Film Electrodes with Ultrahigh Surface Area and Electrochemical Activity Chem. Mater 19(15) 3648-3653.

Koehne J, Li J, Cassell A M, Chen H, Ye Q, Ng H T, Han J and Meyyappan M. (2004) The fabrication and electrochemical characterization of carbon nanotube nanoelectrode arrays. eburnal of Materials Chemistry 14(4) 676-684.

Kralchevsky PA, Nagayama K. (2000) Capillary interactions between particles bound to interfaces, liquid films and biomembranes. Advances in colloid and interface science. 85, 145-192.

Lambrechts M and Sansen WMC. (1992) Biosensors: Microelectrochemical Devices CRC Press.

Lau KKS, Bico J, Teo KBK. (2003) Superhydrophobic carbon nanotube forests. Nanoletters. 3, 1701-1705.

Lee SJ, Anandan V, Zhang G. (2008) Electrochemical fabrication and evaluation of highly sensitive nanorod-modified electrodes for a biotin/avidin system. Biosens. Bioelectron. 23(7), 1117-1124.

Losic D, Gooding JJ, Shapter JG, Hibbert DB, Short K. (2001) The influence of the underlying gold substrate on glucose oxidase electrodes fabricated using self-assembled monolayers. Electroanalysis 13: 1385-1393.

Losic D, Shapter JG, Gooding JJ. (2001) Influence of surface topography on alkanethiol SAMs assembled from solution and by microcontact printing. Langmuir. 17(11), 3307-3316.

Moatti SD, Velho G, Reach G. (1992) Evaluating in vitro and in vivo the interference of ascorbate and acetaminophen on glucose detection by a needle-type glucose sensor Biosensors and Bioelectronics 7(5) 345-352.

Qiao CS, Tuzhi P, Yunu Z, Yang CF. (2005) An Electrochemical Biosensor with Cholesterol Oxidase/ Sol-Gel Film on a Nanoplatinum/Carbon Nanotube Electrode. Electroanalysis. 17: 857-861.

Ramanavicius A, Kausaite A, and Ramanaviciene A. (2005) Polypyrrole-coated glucose oxidase nanoparticles for biosensor design. Sensors and Actuators B: Chemical 111$112532-539$.

Sawaguchi T, Sato Y, Mizutani F. (2001) In situ STM imaging of individual molecules in twocomponent self-assembled monolayers of 3-mercaptopropionic acid and 1decanethiol on Au(111). el Electroanal. Chem. 496(1-2), 50-60.

Trasatti S and Petrii OA. (1991) Real Surface Area Measurements in Electrochemistry Pure and applied chemistry 63(5) 711-734.

Uang YM, Chow TC. (2002) Criteria for Designing a Polypyrrole Glucose Biosensor by Galvanostatic Electropolymerization. Electroanalysis. 14: 1564-1570. 
Wang J, Musameh M. (2003) Carbon Nanotube/Teflon Composite Electrochemical Sensors and Biosensors. Anal. Chem. 75: 2075-2079.

Wang J, Mustafa M. (2004) Carbon nanotube screen-printed electrochemical sensors. Analyst. 129, 1-2.

Wang Z, Su YK, Li HL. (2002) AFM study of gold nanowire array electrodeposited within anodic aluminum oxide template. Applied Physics A. 74, 563-565.

Wang J, Nosang M, Minhee Y, Harold M. (2005) Glucose oxidase entrapped in polypyrrole on high-surface-area Pt electrodes: a model platform for sensitive electroenzymatic biosensors. eburnal of Electroanalytical Chemistry. 575: 139-146.

Walczak MM, Popenoe DD, Deinhammer RS, Lamp BD, Chung C, Porter MD. (1991) Reductive desorption of alkanethiolate monolayers at gold: a measure of surface coverage. Langmuir. 7(11), 2687-2693.

Widrig CA, Chung C, and Porter M D. (1991) The electrochemical desorption of nalkanethiol monolayers from polycrystalline $\mathrm{Au}$ and Ag electrodes. El Electroanal. Chem. 310, 335-359.

$\mathrm{Xu} \mathrm{J}$, Huang X, Xie G. (2004) Study on the structures and magnetic properties of Ni, Co$\mathrm{Al}_{2} \mathrm{O}_{3}$ electrodeposited nanowire arrays. Materials Research Bulletin. 39, 811-818.

Yemini M, Reches M, Rishpon J. (2005) Novel electrochemical biosensing platform using self assembled peptide nanotube. Nanoletters. 5, 183-186.

Zhang G, Anandan V and Rao YL. (2008) Fabrication of microstructures integrated with nanopillars along with their applications as electrodes in sensors. US PTO patent pending, the University of Georgia. 


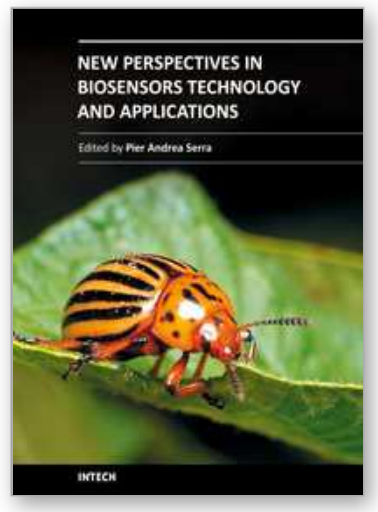

\author{
New Perspectives in Biosensors Technology and Applications \\ Edited by Prof. Pier Andrea Serra
}

ISBN 978-953-307-448-1

Hard cover, 448 pages

Publisher InTech

Published online 27, July, 2011

Published in print edition July, 2011

\begin{abstract}
A biosensor is a detecting device that combines a transducer with a biologically sensitive and selective component. Biosensors can measure compounds present in the environment, chemical processes, food and human body at low cost if compared with traditional analytical techniques. This book covers a wide range of aspects and issues related to biosensor technology, bringing together researchers from 12 different countries. The book consists of 20 chapters written by 69 authors and divided in three sections: Biosensors Technology and Materials, Biosensors for Health and Biosensors for Environment and Biosecurity.
\end{abstract}

\title{
How to reference
}

In order to correctly reference this scholarly work, feel free to copy and paste the following:

Guigen Zhang (2011). Design and Fabrication of 3D Skyscraper Nanostructures and Their Application as Electrodes in Biosensors, New Perspectives in Biosensors Technology and Applications, Prof. Pier Andrea Serra (Ed.), ISBN: 978-953-307-448-1, InTech, Available from: http://www.intechopen.com/books/newperspectives-in-biosensors-technology-and-applications/design-and-fabrication-of-3d-skyscrapernanostructures-and-their-application-as-electrodes-in-biosen

\section{INTECH}

open science | open minds

\section{InTech Europe}

University Campus STeP Ri

Slavka Krautzeka 83/A

51000 Rijeka, Croatia

Phone: +385 (51) 770447

Fax: +385 (51) 686166

www.intechopen.com

\section{InTech China}

Unit 405, Office Block, Hotel Equatorial Shanghai

No.65, Yan An Road (West), Shanghai, 200040, China

中国上海市延安西路65号上海国际贵都大饭店办公楼405单元

Phone: +86-21-62489820

Fax: +86-21-62489821 
(C) 2011 The Author(s). Licensee IntechOpen. This chapter is distributed under the terms of the Creative Commons Attribution-NonCommercialShareAlike-3.0 License, which permits use, distribution and reproduction for non-commercial purposes, provided the original is properly cited and derivative works building on this content are distributed under the same license. 